\title{
CONSIDERAÇÕES SOBRE A INOVAÇÃO EM PMES: O PAPEL DAS REDES E DO EMPREENDEDOR
}

\author{
Thoughts on Innovation in PM ES: \\ the role of Networks and entrepreneur
}

Recebido em 05.08.09 / Aceito em 15.01.10

\section{Cristiane Marques de Mello ${ }^{1}$, Hilka Vier Machado ${ }^{2}$ e Marcos Junio Ferreira de Jesus ${ }^{3}$}

\section{Resumo}

No contexto econômico global, a implantação de inovações contribui para a sobrevivência das empresas. As inovações são decorrentes tanto de mudanças no ambiente interno quanto externo à organização (BAUMOL, 2002; DRUCKER, 1986, 1998, 2002, 2005; LONGENECKER et al., 2007; NONAKA; TAKEUCHI, 1997; SCHUMPETER, 1975, 1982; VAN DE VEN, 2000; ZAWISLAK, 2007). Este ensaio tem o objetivo de discutir as diversas formas de inovação, sua aplicação na pequena empresa e a importância da formação de redes para essas empresas e responder como as PMES podem aumentar o nível de inovação. Transformações no contexto social e econômico servem como ativadores para a criação de processos inovadores, assim também como as inovações podem servir de desencadeador de transformações sociais e econômicas (BARON; SHANE, 2007; BRUYAT; JULIEN, 2000; DAVIDSSON, 2005; FILION, 2004; SHANE; VENKATARAMAN, 2000), como um processo recursivo. A formação de redes

\footnotetext{
1 Mestre em Administração pela Universidade Estadual de Maringá (UEM). Professora da graduação em Administração; da pós-graduação (lato sensu) e atual coordenadora do MBA em Gestão Pública da Faculdade Integrado de Campo Mourão; lecionando também na Faculdade Estadual de Ciências e Letras de Campo Mourão (UNESPAR/ Fecilcam). E-mail: mellcris@gmail.com

2 Doutora em Engenharia de Produção pela Universidade Federal de Santa Catarina (UFSC), com doutorado sandwich na HEC École des Hautes Études Commerciales, em Montreal (2000). Docente do curso de Administração e do Mestrado em Administração da UEM.

3 Mestre em Administração pela UEM. Professor do curso de Administração da UNESPAR/Fecilcam. E-mail: marcos_junio@hotmail.com
} 
pode estimular a inovação em pequenas empresas, possibilitando a disseminação de informações e geração de conhecimento.

Palavras-chave: Inovação; Redes; Pequenas Empresas.

\begin{abstract}
In the global economic context, the implementation of innovations contributes to the companies' survival. Innovations are due to changes in both internal and external environments to the organization (BAUMOL, 2002; DRUCKER, 1986, 1998, 2002, 2005; LONGENECKER et al, 2007; NONAKA; TAKEUCHI, 1997; SCHUMPETER, 1975, 1982; VAN DE VEN, 2000; ZAWISLAK, 2007). This essay aims at discussing the diverse ways of innovation, its application in the small company and the importance of the creation of networks for these companies. It also aims to answer how can PMES increase the level of innovation. Changes in the economic and social context serve as activators to the creation of innovative processes, the same way as innovations may trigger social and economical changes (BARON; SHANE, 2007; BRUYAT; JULIEN, 2000; DAVIDSSON, 2005; FILION, 2004; SHANE; VENKATARAMAN, 2000), as a recursive process. The formation of networks can stimulate the innovation in small companies, allowing the dissemination of information as well as knowledge generation.
\end{abstract}

Keywords: Innovation; Networks; Small Companies.

\title{
1. Introdução
}

Atualmente, o desenvolvimento e a implantação de inovações contribuem, de alguma maneira, para a sobrevivência das empresas. O processo de inovação pode ser desencadeado mediante as informações que o inovador possui. Segundo Luz, Oliveira e Ornelas (2004), as informações são elementos que facilitam o processo de desenvolvimento de novas ideias. Mudanças nos ambientes sociais e demográficos possibilitam a criação e transmissão de informações sobre oportunidades (SHANE, 2003). Assim, as transformações no macroambiente (BARON; SHANE, 2007; BRUYAT; JULIEN, 2000; DAVIDSSON, 2005; FILION, 2004; SHANE; VENKATARAMAN, 2000) podem ser um incentivador para a geração de novas ideias, ao mesmo tempo em que tais inovações podem desencadear modificações ambientais como um processo circular.

Na concepção de Schumpeter (1982), a organização é a responsável por iniciar o processo de inovação, a fim de oferecer ao cliente produtos e serviços competitivos. O autor enfatiza que é o produtor que começa, normalmente, a mudança econômica e estimula os consumidores a buscar novos produtos para atender novas necessidades. Ele também não descarta a possibilidade de que seja o consumidor a iniciar esse processo, pressionando o produtor a atender seus novos anseios. Entretanto, para que a geração de um novo produto tenha viabilidade, é necessário que as necessidades do consumidor sejam vinculadas às capacidades técnicas da organização (DOUGHERTY, 1996). Ou seja, além do conhecimento necessário sobre o consumidor, bem como aquilo que o mesmo deseja, é indispensável que a empresa tenha as habilidades técnicas necessárias para a produção do bem ou serviço que se propõe a oferecer no mercado.

Na implantação de uma empresa ou no desenvolvimento de seus produtos tanto pode haver sucesso como fracasso. Drucker (1998) alerta que nos dois casos o empresário precisa considerar o evento como uma chance para a inovação. Ele acrescenta, ainda, que o inesperado leva o indivíduo a sair de seus pressupostos, das ideias preconcebidas, e é isso que faz o inesperado ser tão propício à inovação. 
As mudanças tecnológicas também podem ser incentivadoras de inovações, como é o caso da invenção da Internet, que fez com que as pessoas criassem novas combinações de recursos (SHANE, 2003). Atualmente é possível a comunicação global de forma rápida, sem uso de linha telefônica e em tempo real. As informações via online movimentam-se de forma ágil e contínua, possibilitando seu acesso a um grande número de pessoas simultaneamente. Tanto indivíduos como as organizações podem usufruir dessa vantagem e utilizá-la em benefício próprio ou organizacional.

O Brasil é constituído, na sua maioria, por micro e pequenas empresas. Segundo dados do Sebrae (2006), de 1996 a 2002, essas empresas representavam 57,2\% dos empregos formais no país. É inegável a sua importância para os estudos organizacionais e para o avanço do conhecimento na área da gestão de empresas. Estatísticas do Sebrae apontam que o número de pequenas empresas em atividade, entre 1996 e 2002, elevou-se de 181.115 para 274.009, tendo um crescimento de $51,3 \%$. O número de pessoas que trabalham nas pequenas empresas passou de 4.054.635 para 5.789.875, resultando num crescimento de 42,8\%, evoluindo a participação percentual no total de empregos de $18,8 \%$ para $21,0 \%$. Juntas, as micro e pequenas empresas, em 2002, eram responsáveis por $99,2 \%$ do número total de empresas formais, por $57,2 \%$ dos empregos totais.

As pequenas empresas, diferentes das grandes, não dispõem de uma ampla quantidade de recursos destinados ao processo de inovações, dificilmente possuem um setor de pesquisa e desenvolvimento e, na maioria das vezes, vivem cercadas de incertezas pelas alterações na política econômica, pela diminuição do tempo de vida do produto, pelos concorrentes que possuem maior vantagem competitiva, entre outros fatores. Tais circunstâncias levam a pensar que empresas desse porte tendem a ser menos inovadoras que as grandes corporações. Entretanto, Nonaka e Takeuchi (1997) acreditam que viver cercado de situações de incertezas favorece as empresas e as fazem buscar conhecimento externo à organização, e isso leva à inovação contínua. Desse modo, a questão que embasa este ensaio é como PMES podem aumentar o nível de inovação.

Mediante a atual importância do tema do artigo, este ensaio tem como objetivo principal discutir as diversas formas de inovação, bem como sua aplicação na pequena empresa, destacando a importância do indivíduo e da formação de redes no processo de inovação.

A inovação, no presente trabalho, é também considerada como uma oportunidade empreendedora. As oportunidades empreendedoras, na concepção de Shane e Venkataraman (2000), são as situações nas quais novos bens ou serviços, e novos métodos organizacionais podem ser introduzidos e vendidos por um preço maior que o custo de produção, em que os indivíduos podem criar uma nova estrutura recombinando recursos (SHANE, 2003).

O escopo do artigo está dividido da seguinte forma: o primeiro assunto a ser abordado, na seção 2, é inovação e empreendedorismo; seguido da importância da informação e do conhecimento no processo de inovação; e uma breve discussão sobre algumas formas de inovação. A seção 3 trata do papel do indivíduo na inovação. Posteriormente, na seção 4, os assuntos a serem tratados são: inovação na empresa de pequeno porte, importância das redes para esse tipo de organização e estudos sobre redes desenvolvidos em pequenas empresas. Por fim, na seção 5, são feitas as considerações finais. 


\section{Inovação e empreendedorismo}

O estudo sobre inovação tem sido foco de disciplinas, como a economia, sociologia e gestão (FORT; RASTOIN; TEMRI, 2005), e não se caracteriza como um objeto singular de estudo da administração ou do empreendedorismo.

A inovação é uma das características que mais aparecem nas definições sobre empreendedorismo de autores tradicionais. Souza (2005) fez uma análise das características empreendedoras abordadas por diversos autores, entre eles estão Schumpeter, McClelland, Weber, Filion e McDonald. Como elemento comum a todos, estava a inovação, apesar desses autores pertencerem a correntes epistemológicas diferentes (ver seção 4).

Muitas vezes as dificuldades enfrentadas pelas empresas podem pressioná-las e conduzilas a mudanças no produto, serviço ou no processo produtivo. De acordo com Nonaka e Takeuchi (1997), as empresas japonesas são expertises em promover a inovação. Os autores comentam que o Japão passou por grandes e complexas adversidades, como a Segunda Guerra Mundial, Guerra da Coreia, Guerra do Vietnã, crise do petróleo, crise do iene, e outras instabilidades externas que ocorreram nos últimos 50 anos. Além disso, havia transformações no mercado, avanço tecnológico, aumento da concorrência e obsoletismo dos produtos, e um cenário em que só havia dúvidas e insegurança. Todos esses fatores, segundo os autores, impulsionaram os japoneses a inovar, aperfeiçoar-se e a implantar contínuas melhorias. Para eles, realizar a inovação contínua denota "olhar para fora e para o futuro" (NONAKA; TAKEUCHI, 1997, p. 4). Olhar para fora e para o futuro pode significar ver mercados ainda inexplorados, pois, como lembra Kisfalvi (2002), existem diferentes produtos para diferentes mercados, e o empreendedorismo consiste nos comportamentos competitivos que dirigem o processo de mercado (DAVIDSSON, 2005). A inovação sistemática consiste na busca deliberada e organizada de mudanças e na constante e ordenada análise das oportunidades que tais mudanças podem oferecer para a inovação econômica ou social (BARON; SHANE, 2007; DRUCKER, 2002).

As inovações são decorrentes tanto de mudanças no ambiente interno à organização quanto do ambiente fora da organização (BAUMOL, 2002; DRUCKER, 1986, 1998, 2002, 2005; LONGENECKER et al., 2007; NONAKA; TAKEUCHI, 1997; SCHUMPETER, 1975, 1982; VAN DE VEN, 2000; ZAWISLAK, 2007). Fala-se de inovação como um processo de aprendizagem provindo da inter-relação de diversos agentes, tanto internos como externos (FORT; RASTOIN; TEMRI, 2005). As transformações dos ambientes impulsionam a criação de novas ideias e surgimento de novos conhecimentos por meio do aprendizado intencional ou não-intencional, e a inovação é o resultado da aprendizagem, que, em grande parte, provém da experiência e do experimento (MAYO, 2003). Lima (2000) menciona que a inovação se origina da busca e/ou geração de oportunidades ou das mudanças situacionais; além disso, ela representa uma vantagem competitiva para a empresa.

Assim, Nonaka e Takeuchi (1997) afirmam que, para compreender a inovação, é necessário entender a teoria do conhecimento. Os autores lembram que as organizações criam novos processos, novos produtos e novas formas de organizar, mas enfatizam que há a necessidade de entender de que forma as organizações geram o novo conhecimento que possibilita essas criações. A importância da informação e da geração do conhecimento no processo de inovação será abordada na seção subsequente. 


\subsection{A importância da informação e do conhecimento no processo de inovação}

A utilização da informação pelas organizações é um elemento indispensável, ela é subsídio para a tomada de decisões, além de permitir a previsão de tendências referentes aos objetivos e metas, bem como mercado, P\&D e inovações (LUZ; OLIVEIRA; ORNELAS, 2004).

$\mathrm{O}$ inter-relacionamento dos membros organizacionais contribui para a aquisição e disseminação das informações. Conforme Shane (2003), a interação com outras pessoas facilita o acesso à informação. O poder de inovar está, por um lado, na capacidade de se adquirir informação por meio de interações com o ambiente, especialmente a inserção em redes e, por outro lado, na capacidade de integrar e tratar esta informação, através de interações internas para produzir conhecimento novo (FORT; RASTON; TEMRI, 2005).

As informações podem ser provenientes tanto do ambiente interorganizacional quanto do ambiente extraorganizacional. De acordo com Luz, Oliveira e Ornelas (2004), há duas fontes de informação utilizadas por empresas inovadoras: as internas e as externas. Podem ser consideradas fontes internas: diferentes áreas da empresa e outra empresa pertencente ao grupo. Têm-se como fontes externas: os concorrentes, clientes, fornecedores, informações públicas, universidades, institutos de pesquisa e tecnologia. Para Nonaka e Takeuchi (1997), a organização precisa fazer mais do que apenas processar informações, ela necessita gerar conhecimento. Além disso, eles enfatizam que os indivíduos organizacionais precisam ser agentes ativos da inovação. Os autores relacionam o êxito das empresas japonesas com a sua capacidade de gerar novos conhecimentos, disseminá-los em toda a organização e, ainda, coligá-los aos bens, serviços e sistemas.

Nos últimos quarenta anos, as indústrias passaram da distribuição de bens para a distribuição do conhecimento, e as indústrias que conseguiram crescer nesse período obtiveram crescimento devido a sua adequação em volta do conhecimento e informação (DRUCKER, 2002).

As possibilidades de crescimento das micros, pequenas e médias empresas (MPMEs) estão relacionadas ao seu sistema de conhecimento (LA ROVERE, 2001). O conhecimento é considerado um dos fatores primordiais ao processo de inovação. Ter conhecimento sobre o mercado facilita as descobertas de oportunidades (SHANE, 2003) e, consequentemente, a possibilidade de inovar.

Segundo Nonaka e Takeuchi (1997), dois tipos de conhecimento são considerados: o conhecimento tácito, mais enfatizado pelos orientais; e o conhecimento explícito, mencionado com maior ênfase pelos ocidentais. Os orientais consideram o conhecimento tácito mais do que números e palavras. Esse tipo de conhecimento é muito pessoal e está arraigado nas ações e experiências do indivíduo. Envolve a dimensão técnica e cognitiva da pessoa. No caso do conhecimento explícito, ele pode ser armazenado e transmitido por um computador. Para o tácito se tornar explícito, é necessário que seja convertido em palavras ou números, de modo que todos possam entender. Quando ocorre essa transformação e novamente de explícito para tácito, o conhecimento organizacional é, então, gerado. Esse conhecimento ocorre a partir do indivíduo e sua interação com outros.

A informação é um fluxo de mensagens que gera o conhecimento, apoiado nas crenças e compromissos de quem o detém. Quando há a inter-relação dos conhecimentos tácito e explícito, surge a inovação (NONAKA; TAKEUCHI, 1997).

Mayo (2003) considera que a finalidade da inovação é mais que se ter ideias inovadoras, é também a geração de lucro futuro. Cada etapa do processo inovativo requer recursos, porque 
envolve custos que poderão vir a não proporcionar o retorno esperado. Para amenizar esse fator de risco, Mayo sugere que os participantes do projeto de inovação estejam em contato com os próprios clientes e tenham conhecimento do negócio, a fim de avaliarem custos e retornos. De acordo com Barbieri (1997), a fase da implementação da inovação exige custos significativos para a organização, valor que pode ser aumentado quando a empresa se utiliza de tecnologia desenvolvida por outra empresa. Somente uma teoria econômica que tem o conhecimento como recurso econômico será capaz de explicar o crescimento econômico e a inovação, sendo as mais arriscadas as baseadas no conhecimento científico e na tecnologia (DRUCKER , 1998, 2002, 2005).

É necessário que as organizações desenvolvam capacidades de aprendizagem distintas, como capacidade de mudança de mercado, por meio do monitoramento de mudanças nas preferências dos clientes e nas ações dos concorrentes (MORT; WEERAWARDENA; CARNEGIE, 2003), possibilitando, desse modo, o desenvolvimento de processos inovativos.

Não há apenas um tipo de inovação, há aquelas que são inéditas ou exclusivas, como também as incrementais. Na seção seguinte, serão abordadas formas de inovação, conceituadas por diferentes autores.

\subsection{As múltiplas formas de inovação}

Para Nonaka e Takeuchi (1997), o melhor aprendizado vem com a experiência direta. O conhecimento novo é criado na inter-relação da empresa com o meio externo. O aprendizado dessa relação precisa ser interiorizado e ajustado à identidade da empresa. Esses novos conhecimentos proporcionam à empresa contínua renovação de ideias, estimulando as inovações. Há quatro modos de aprendizagem segundo Mayo (2003): i) educação: que está relacionado ao conhecimento e percepções que modificam o mapa mental dos indivíduos - é uma forma de aprendizagem ligada à mente; ii) treinamento; iii) experiência e iv) aprendizagem com outros, como exemplos, têm-se as experiências compartilhadas e os treinamentos recebidos por meio de outros.

Os conhecimentos já existentes dão origem a novos conhecimentos. Aplicação da competência especializada já existente a uma nova forma de aplicação, uma extensão do que já existe, é considerada uma forma de inovação (DRUCKER, 1998).

Drucker (1998) considera sete fontes para o surgimento de oportunidade inovadora, que são divididas em dois grupos. Quatro fontes situam-se internas à empresa e três localizamse no ambiente externo à empresa. No primeiro grupo estão: o inesperado, a incongruência, a inovação baseada na necessidade do processo e as mudanças na estrutura do setor industrial ou do mercado. Pertencentes ao segundo grupo estão as mudanças demográficas: mudanças em percepção, disposição e significado e conhecimento novo científico e não-científico.

As oportunidades inovadoras não necessariamente estão ligadas somente à criação de organizações ou abertura de empresas. O foco de estudo de empreendedorismo está além do estudo de novas organizações, contempla também a investigação de novos mercados por diferentes modos de exploração, que tanto podem ser inovadores como imitadores (DAVIDSSON, 2005).

Fazer novas combinações quer dizer usar de maneira diferente os meios de produção que existem no sistema econômico (SCHUMPETER, 1982). As novas combinações, de acordo com este autor, são: 
0 desenvolvimento de um novo produto ou serviço;

प[ novo método de produção;

प0 abertura de um novo mercado;

प्र nova fonte de ofertas de bens semimanufaturados ou matéria-prima;

प0 novas formas de organizar.

A criação de um novo produto pode gerar ou estimular a invenção de outros novos produtos, como, por exemplo, a criação do computador proporcionou a fabricação de microchips (SHANE, 2003).

Para Mayo (2003), a inovação engloba: mudanças pessoais e organizacionais; contínuo aperfeiçoamento do processo; exploração de novas formas de trabalho, novos fornecedores e novas tecnologias; aprendizagem por meio de outros; criação de novos mercados, de novas relações e de novas alianças; novas estratégias de preços; novas formas de gerenciar e medir desempenho.

No quadro 1, são apresentadas algumas definições de inovação na visão de diferentes autores.

\begin{tabular}{|l|l|}
\hline \multicolumn{1}{|c|}{ Autores } & \multicolumn{1}{c|}{ Definição de inovação } \\
\hline Barbieri (1997) & $\begin{array}{l}\text { A inovação é um novo processo produtivo ou modificação no mesmo; mudanças no } \\
\text { produto ou substituição por outro com as mesmas funções e/ou acrescidas de outras; } \\
\text { geração de novos produtos e novos produtos advindos de novas tecnologias. }\end{array}$ \\
\hline Dougherty (1996) & $\begin{array}{l}\text { A inovação pode envolver o significado de novos clientes, novos usos, nova estrutura } \\
\text { de manufatura, nova logística, nova tecnologia do produto ou qualquer combinação } \\
\text { desses elementos. }\end{array}$ \\
\hline Mayo (2003) & A inovação é uma forma de constante aperfeiçoamento. \\
\hline Drucker (1998) & A inovação é a aplicação do conhecimento para a produção de novo conhecimento. \\
\hline $\begin{array}{l}\text { Mort, Weerawardena e } \\
\text { Carnegie (2003) }\end{array}$ & A inovação é uma aquisição de conhecimento e processo de integração. \\
\hline
\end{tabular}

Quadro 1 - Definições de inovação

\section{O papel do indivíduo na inovação}

Nesse tópico, será enfocado o papel exercido pelo empreendedor no processo de inovação. Os empreendedores são considerados como agentes de mudança e movem a economia criando novos mercados ou novas maneiras de fazer as coisas (SCHUMPETER, 1982; MORT; WEERAWARDENA; CARNEGIE, 2003).

O empreendedor é responsável pelo processo de criação de uma inovação e sem o indivíduo não há criação de processo inovativo (BRUYAT; JULIAN, 2000). Inovação está diretamente ligada ao empreendedor, pois uma das suas características essenciais é a capacidade de inovar. As inovações ou combinações novas são chamadas por Schumpeter (1982) de empreendimento, e aqueles que realizam essas inovações são denominados de empresários. Segundo o autor, empresários são tanto os homens de negócios independentes, quanto os empregados de empresas que criam combinações novas.

Nem todos irão explorar a oportunidade da mesma forma, pois as pessoas possuem diferenças individuais, e a decisão de explorar uma oportunidade empreendedora é influenciada por essas diferenças (SHANE; VENKATARAMAN, 2000). As diferenças individuais são constituídas 
por características demográficas, educação, características psicológicas, motivações, personalidade e processo cognitivo (SHANE, 2003).

Novas descobertas partem de conhecimento já existente (SCHUMPETER, 1982), como, por exemplo, as pessoas que trabalham com pesquisa e desenvolvimento (P\&D) têm maior probabilidade de terem novas ideias sobre tecnologia. A experiência reduz incertezas, facilita a formulação de estratégias empreendedoras, a aquisição de recursos e o processo de organização (SHANE, 2003).

A formulação de muitas estratégias empresariais está relacionada com as características pessoais do empreendedor, com sua vivência passada, com seus erros e seus acertos, seus êxitos e seus fracassos. A história de vida e as experiências do empreendedor são transferidas para os negócios (KISFALVI, 2002) e tanto podem ser fator contributivo para o êxito das ações empreendedoras como podem ser fator limitante das atitudes do empreendedor. $\mathrm{O}$ empreendedor é caracterizado por Souza (2005, p. 137) como:

[...] um líder com competências especiais para tratar: a complexidade das atividades cotidianas, advindas da necessidade de atender altos níveis de qualidade e de satisfação da sociedade; canalizar as atividades cotidianas em direção ao sucesso estratégico da empresa; aceitar e promover, dentro do enfoque de responsabilidade social, a ética e os princípios morais e ecológicos para todos os membros da empresa, como um fator de competitividade e sucesso.

A liderança não está somente em descobrir ou criar o novo, mas em deixar o grupo social impressionado a ponto de conduzi-lo em sua direção (SCHUMPETER, 1982). A inovação contínua está relacionada com o engajamento e comprometimento dos atores organizacionais. Segundo Dougherty (1996), para haver o desenvolvimento contínuo de novos produtos, os membros da organização devem estar comprometidos com a inovação. Barbieri (1997) comenta que a busca por um contínuo aperfeiçoamento precisa da contribuição de todos. Drucker (2002) sugere que as pessoas façam associações dos conhecimentos existentes para a resolução de problemas e comenta, ainda, que as pessoas devem utilizar os múltiplos conhecimentos que possuem, pois, na maioria das vezes, as empresas já têm o conhecimento de que necessitam.

Para Shane (2003) e Shane e Venkataraman (2000), pessoas com propensão a assumir riscos são mais prováveis de explorar oportunidades empreendedoras. Shane e Venkataraman (2000) comentam que onde a maioria das pessoas vê riscos, os empreendedores visualizam oportunidades. E, em um contexto de inovação e acirrada concorrência, é certo que há uma procura por gestores capazes de se adequarem às mudanças na produção e no mercado (SOUZA, 2005).

Conforme Fort, Rastoin e Temri (2005), nos pequenos negócios, o papel do líder parece ser principal na construção das capacidades: de obter informações através da inter-relação com o ambiente e de utilizar essas informações para a geração de novos conhecimentos. As relações que ele mantém com seus diferentes sócios parecem também determinar sua capacidade para adquirir conhecimento.

\section{A inovação na empresa de pequeno porte}

A maioria dos empreendimentos brasileiros é constituída como micro e pequena empresa. O quadro 2 apresenta a classificação das empresas pelo porte. No Brasil, a classificação das 
micro e pequenas empresa mediante a receita bruta anual está no Estatuto de 1999. Os valores foram atualizados pelo Decreto no. 5.028/2004, de 31 de março de 2004. Para a microempresa, o valor da receita bruta anual é igual ou inferior a $R \$ 433.755,14$ (limite que anteriormente era de $R \$ 244.000,00)$. Para a empresa de pequeno porte, a receita bruta anual é superior a $R \$$

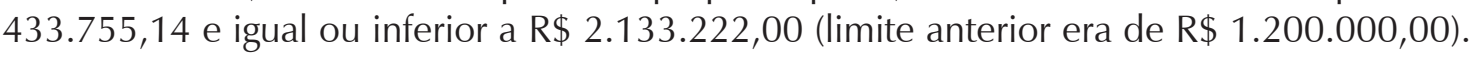

\begin{tabular}{|l|l|}
\hline Porte & Número de empregados \\
\hline Microempresa & $\begin{array}{l}\text { Indústria - até } 19 \text { pessoas; } \\
\text { Comércio e serviços - até 09 pessoas. }\end{array}$ \\
\hline Pequena empresa & $\begin{array}{l}\text { Indústria - de } 20 \text { a } 99 \text { pessoas; } \\
\text { Comércio e serviços - de } 10 \text { a } 49 \text { pessoas. }\end{array}$ \\
\hline Média empresa & $\begin{array}{l}\text { Indústria - de } 100 \text { a } 499 \text { pessoas; } \\
\text { Comércio e serviços - de } 50 \text { a } 99 \text { pessoas. }\end{array}$ \\
\hline Grande empresa & $\begin{array}{l}\text { Indústria - acima de } 499 \text { pessoas; } \\
\text { Comércio e serviços - acima de } 99 \text { pessoas. }\end{array}$ \\
\hline
\end{tabular}

Quadro 2 - Classificação das empresas pelo porte

As políticas de apoio às MPMEs são horizontais, normalmente centradas em empresas isoladas, e visam suprir deficiências de informação e de crédito destas empresas (LA ROVERE, 2001). A fonte de informação mais utilizada é a fonte interna. Mediante o estudo realizado por Luz, Oliveira e Ornelas (2004), foi constatado que as pequenas e médias empresas inovadoras, tanto europeias como brasileiras, usam fontes iguais de informação, tendo como dominante a fonte interna, seguida por clientes, fornecedores, feiras, exposições e concorrentes.

Em um estudo realizado por Souza (2005), foram identificadas características vinculadas às definições do empreendedor e empreendedorismo, focado no desenvolvimento de pequenas empresas, como mostrado no quadro 3.

\begin{tabular}{|c|c|c|c|c|c|c|c|c|c|c|c|c|c|c|c|c|c|}
\hline \multirow[b]{2}{*}{ Caracteríticas } & \multicolumn{17}{|c|}{ Autores } \\
\hline & 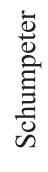 & 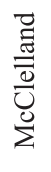 & $\begin{array}{l}\bar{\Delta} \\
\frac{\Delta}{0} \\
\dot{z} \\
\dot{\Sigma}\end{array}$ & 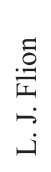 & 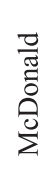 & 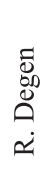 & $\begin{array}{l}0 \\
0 \\
0 \\
0\end{array}$ & $\frac{\frac{\pi}{\pi}}{\frac{\pi}{\pi}}$ & 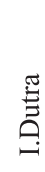 & 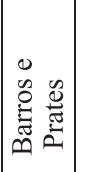 & 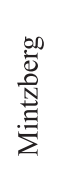 & 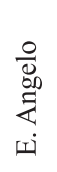 & 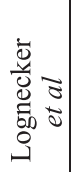 & 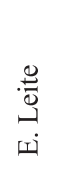 & 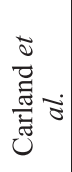 & 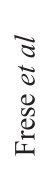 & 苞 \\
\hline $\begin{array}{l}\text { Buscar } \\
\text { oportunidades }\end{array}$ & $\mathrm{X}$ & $\mathrm{X}$ & & $\mathrm{X}$ & $\mathrm{X}$ & $\mathrm{X}$ & $\mathrm{X}$ & & $\mathrm{X}$ & & $\mathrm{X}$ & $\mathrm{X}$ & $\mathrm{X}$ & $\mathrm{X}$ & & & 11 \\
\hline $\begin{array}{l}\text { Conhecimento } \\
\text { do mercado }\end{array}$ & & & & & & $\mathrm{X}$ & $\mathrm{X}$ & $\mathrm{X}$ & & & & $\mathrm{X}$ & & $\mathrm{X}$ & & & 5 \\
\hline $\begin{array}{l}\text { Conhecimento } \\
\text { do produto }\end{array}$ & & & & & & $\mathrm{X}$ & $\mathrm{X}$ & $\mathrm{X}$ & & & & $\mathrm{X}$ & & $\mathrm{X}$ & & & 5 \\
\hline Correr riscos & $\mathrm{X}$ & $\mathrm{X}$ & & $\mathrm{X}$ & $\mathrm{X}$ & $\mathrm{X}$ & $\mathrm{X}$ & & & & $\mathrm{X}$ & $\mathrm{X}$ & & $\mathrm{X}$ & $\mathrm{X}$ & & 10 \\
\hline Criatividade & & $\mathrm{X}$ & & $\mathrm{X}$ & & $\mathrm{X}$ & & $\mathrm{X}$ & $\mathrm{X}$ & $\mathrm{X}$ & & $\mathrm{X}$ & & $\mathrm{X}$ & $\mathrm{X}$ & & 9 \\
\hline Iniciativa & $\mathrm{X}$ & $\mathrm{X}$ & & $\mathrm{X}$ & & & & & $\mathrm{X}$ & & & & & $\mathrm{X}$ & & $\mathrm{X}$ & 6 \\
\hline Inovação & $\mathrm{X}$ & $\mathrm{X}$ & $\mathrm{X}$ & $\mathrm{X}$ & $\mathrm{X}$ & $\mathrm{X}$ & $\mathrm{X}$ & $\mathrm{X}$ & $\mathrm{X}$ & $\mathrm{X}$ & $X$ & $\mathrm{X}$ & $\mathrm{X}$ & $\mathrm{X}$ & $\mathrm{X}$ & $\mathrm{X}$ & 16 \\
\hline Liderança & $\mathrm{X}$ & $\mathrm{X}$ & $\mathrm{X}$ & $\mathrm{X}$ & $X$ & & $\mathrm{X}$ & & & & $\mathrm{X}$ & & & & & & 7 \\
\hline $\begin{array}{l}\text { Necessidade de } \\
\text { realização }\end{array}$ & $\mathrm{X}$ & $\mathrm{X}$ & & & & & & & & & $\mathrm{X}$ & & & & $\mathrm{X}$ & $\mathrm{X}$ & 5 \\
\hline Pró-atividade & $\mathrm{X}$ & $\mathrm{X}$ & & $\mathrm{X}$ & & & & & & & & & & & $\mathrm{X}$ & $\mathrm{X}$ & 5 \\
\hline Visionário & & & & $\mathrm{X}$ & & & & & $\mathrm{X}$ & & $\mathrm{X}$ & & & $\mathrm{X}$ & & $\mathrm{X}$ & 5 \\
\hline
\end{tabular}

Quadro 3 - Matriz de características de empreendedor e empreendedorismo Fonte: Souza (2005, p. 143). 
Esses resultados apontam que a 'inovação' é a característica empreendedora mais citada pelos mais diversos autores. Isso implica dizer que a inovação está relacionada, essencialmente, com os conceitos de empreendedorismo. A 'busca de oportunidades' aparece citada por 11 dos 16 autores pesquisados e, em terceiro lugar, pode-se visualizar a característica 'correr riscos'. Em especial essas três características podem ser vistas como complementares. A busca de oportunidades pode resultar em inovação inédita ou parcial, pode ser em relação a um produto ou serviço, uma nova forma de organizar ou uma recombinação de recursos, entretanto, a inovação implica em correr riscos.

A 'criatividade e a liderança' também são aspectos de grande relevância no contexto das pequenas empresas. Partindo do pressuposto de que as pequenas empresas possuem uma menor quantidade de recursos que médias e grandes empresas, a criatividade, na maioria das vezes, poderá ser utilizada para superação da concorrência, para a ampliação dos negócios, para a economia dos recursos produtivos e sobrevivência no mercado. A criatividade pode ser incentivada pela liderança ou partir dela própria.

Schumpeter (1982) menciona que o líder empresarial encaminha os meios de produção para novos canais. Aqueles que têm uma elevada necessidade por realização são mais prováveis de explorar oportunidades (SHANE; VENKATARAMAN, 2000).

De acordo com Luz, Oliveira e Ornelas (2004), a maioria das micro e pequenas empresas (MPEs) cria ou adota inovações somente no momento em que percebem as oportunidades de negócio ligadas à inovação ou, ainda, pelo fato de estarem sendo pressionadas pelos clientes ou seus fornecedores. Os autores destacam que isso acontece por causa das particularidades do processo de aprendizado tecnológico das MPEs, que é limitado pelo tempo e pessoal disponível.

Lima (2000) menciona que as pequenas empresas proporcionam aos seus membros maior responsabilidade e controle, fazendo com que haja empenho, por parte dos mesmos, no cumprimento da missão organizacional. Entretanto, Kisfalvi (2002) comenta que, especialmente em pequenas empresas, os empresários se engajam pouco no planejamento, mais em ações e menos em formalidade. A inovação necessita de empenho sistemático e elevado nível de organização.

Apesar disso, Drucker (1998) comenta que diversas empresas começaram a ter sucesso quando não esperavam que isso pudesse acontecer. Algumas dessas empresas souberam aproveitar a oportunidade, atendendo ao mercado, e outras não. Umas inovaram seu modo de administrar e se adaptaram às circunstâncias, outras não. Por exemplo, a IBM, que não acreditava na ideia da proliferação dos computadores de pequeno porte, lançou o seu em 1980, tornandose líder mundial três anos depois.

Segundo Lima (2000), a criação de novos empreendimentos de pequeno porte não necessariamente traz algum tipo de inovação. Contudo, Luz, Oliveira e Ornelas (2004) enfatizam que, embora as empresas de grande porte tenham maior capacidade de recursos para inovação, as pequenas empresas possuem maior adaptabilidade às mudanças do mercado.

Uma política de inovação voltada para as MPMEs, como menciona La Rovere (2001), precisa levar em consideração as especificidades dessas empresas, que exigem a articulação entre os governos federal, estadual e local, o que é difícil de ser alcançado. Desse modo, podese dizer que o processo de inovação requer colaboração, inter-relação e alianças entre organizações e governos. As MPMEs irão diferir em relação a sua capacidade inovadora, dependendo da percepção do risco do negócio, da amplitude de planejamento das organizações e da sua consciência referente aos benefícios advindos da inovação. Assim, uma política de inovação voltada para essas empresas requer um frequente controle das iniciativas e resultados alcançados (LA ROVERE, 2001). Embora essas iniciativas sejam fundamentais para a capacitação 
tecnológica das MPMEs, não são eficazes para maximizar os laços de cooperação entre empresas e entre instituições e empresas.

As instituições voltadas para a educação aparecem como suporte para as organizações inovadoras, como lócus de pesquisa e desenvolvimento de novas descobertas. Shane (2003) enfatiza a importância das instituições educacionais, as quais conduzem pesquisas científicas que irão resultar na criação de novos conhecimentos, que é a base de muitas oportunidades empreendedoras. Vale ressaltar, no entanto, que nem sempre essas oportunidades são visualizadas pelos empresários, e a interação com essas instituições pode ficar cada vez menor e mais distante. É possível, ainda, tentar minimizar essa carência de interação através da formação de redes para as pequenas empresas, como comentado a seguir.

\subsection{Importância da formação de redes para PMEs}

É comumente apontado na literatura que o ambiente empresarial tem se tornado mais competitivo e complexo, fazendo com que as empresas de menor porte procurem desenvolver estratégias para se tornarem mais competitivas (FERREIRA; OLIVA; 2006; HOFFMANN; MORALES, 2006). Para melhor compreensão sobre as escolhas e decisões tomadas pelo empreendedor, é preciso considerar o ambiente no qual ele está inserido (BRUYAT; JULIAN, 2000). O desenvolvimento econômico de uma nação é influenciado diretamente por diversas características de suas empresas e pelo ambiente no qual tais empresas estão inseridas (SILVA, 2005).

Estudos recentes têm mostrado a importância da formação de redes, sob diferentes visões, pertencentes a diferentes vertentes, em especial estudiosos da área de empreendedorismo têm se dedicado a escrever sobre o assunto. As redes de cooperação tem sido um meio para as PMEs se ajustarem às exigências do mercado e tornarem-se competitivas.

Souza (2005) comenta que, em diversos estudos, características como autoconfiança, pró-atividade e uso de estratégias de influência, como redes de contatos, são consideradas com alto grau de relevância para o empreendedor. A formação de redes pode ser um incentivador para as pequenas empresas, quando elas têm a possibilidade de obter informações e gerarem conhecimento, aspecto de extrema importância para a geração de inovações, conforme discutido anteriormente na seção 2.1. A rede, de acordo com Fort, Rastoin e Temri (2005), é caracterizada pela interação externa, aprendizagem e processo de inovação.

Rodan e Galunic (2004) afirmam que heterogeneidade de conhecimento é útil para inovação, até mesmo quando as redes forem densas, pois os resultados de sua pesquisa apontam em que a variedade de conhecimento na qual os dirigentes estão expostos é um aspecto importante para o desempenho administrativo global e, especialmente, para o desempenho de inovação.

Maillat (1994 apud FORT; RASTOIN; TEMRI, 2005, p. 52), caracteriza cinco dimensões de uma rede inovadora:

- dimensão organizacional: modo específico de organizar;

- dimensão temporal: relações baseadas em confiança mútua;

- dimensão cognitiva: relações permanentes e desenvolvimento do processo de aprendizagem coletivo;

- dimensão normativa: construção de regras comuns;

- dimensão territorial: proximidade como fator favorável à inovação. 
Em estudo realizado por Balestrin e Vargas (2004) sobre a utilização de redes como estratégias para o melhoramento do desempenho competitivo das pequenas empresas, ficou constatado que a aprendizagem coletiva ocorre na rede tanto pela interação das empresas quanto pela participação em cursos, palestras e serviços de consultorias.

As fontes formais, como revistas, relatórios técnicos, normas técnicas, marcas e patentes, são pouco utilizadas e menos valorizadas para a busca de informações. Este pode ser o motivo da pouca importância conferida às instituições de pesquisa e aos serviços de informação para a indústria, que possuem grande dificuldade em constituir um canal de comunicação com as empresas que tenham maior fluidez e eficácia (LUZ; OLIVEIRA; ORNELAS, 2004). De acordo com La Rovere (2001), mesmo no caso de programas em que as empresas interagem com instituições de ensino e pesquisa, os contatos são esporádicos e ainda focados em problemas individuais das empresas.

As redes de cooperação têm grande relevância para o desenvolvimento brasileiro econômico e social, valorizando micro e pequenas empresas como agentes desse desenvolvimento e fortalecendo estruturas locais e regionais (SILVA, 2005). O estabelecimento de redes pode melhorar a comunicação entre as pequenas empresas (FORT; RASTOIN; TEMRI, 2005; LA ROVERE, 2001). Como elucida La Rovere (2001), o estabelecimento de redes pode impulsionar o crescimento das empresas. No momento em que o conhecimento é essencial, no novo paradigma tecnológico para a competitividade, pequenas empresas podem fomentar sua competitividade através dos laços de cooperação com outras empresas e instituições. As redes tanto são responsáveis pela produção de valor estratégico quanto pela produção de legitimidade (DACIN; OLIVER; ROY, 2007).

É necessário que o apoio às MPMEs seja centrado no estímulo à formação e consolidação de redes. A fim de que as perspectivas de crescimento das MPMEs sejam concretizadas em termos de geração de renda e empregos qualificados, as políticas de apoio a essas empresas necessitam mudar seu foco de empresas isoladas e buscar a formação de redes que encorajem a atividade inovadora (LA ROVERE, 2001). As atividades relacionadas ao processo de inovação precisam ser compreendidas e aceitas pelos empregados, a fim de que sejam legitimadas, em vez de serem impostas, é ainda esperado que haja uma responsabilidade coletiva (DOUGHERTY, 1996).

Por meio de uma rede de relações (Figura 1), o empreendedor consegue recursos e legitimidade. Desse modo, se o empreendedor não tem recursos (que podem ser humanos, sociais, financeiros, físicos, tecnológicos e/ou organizacionais) e nem um demonstrativo de resultados anteriores, uma das alternativas é utilizar-se de uma rede de relacionamentos que possibilite o acesso aos recursos, e que assegure a legitimidade (ROSSONI; TEIXEIRA, 2006).

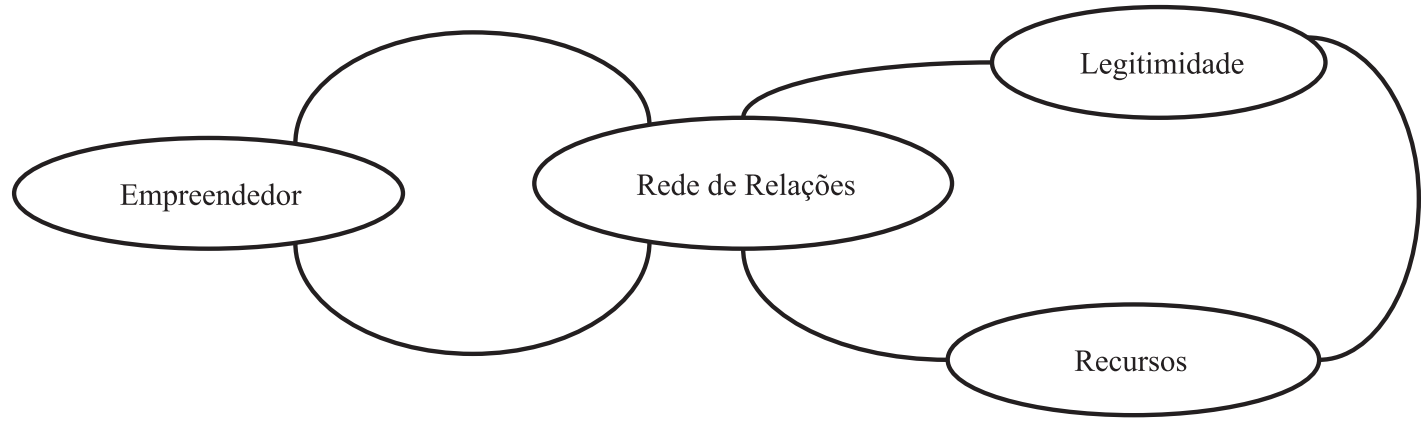

Figura 1 - Arcabouço analítico da construção relacional de legitimidade e recursos Fonte: Rossoni e Teixeira (2006, p. 8). 
Rossoni e Teixeira (2006) enfatizam que tais relações são fortalecidas à medida que o indivíduo responde conforme as regras estabelecidas, legitimando, assim, suas ações. Os autores chamam a atenção para o fato de que a relação entre o empreendedor, a rede de relações, a legitimidade e recursos é circular, de modo que todos esses fatores são retroalimentados. Caso esse processo recursivo seja de algum modo interrompido, o empreendedor terá dificuldades em ter acesso aos recursos disponíveis e em conseguir novos contatos.

Legitimidade social aumenta a possibilidade de recursos das empresas ou acesso a esses recursos (DACIN; OLIVER; ROY, 2007).

Essa tendência associativa (formação de redes) tem repercussão nos setores tradicionais e no segmento das micro e pequenas empresas, em que a busca da ação cooperada parece ser fundamental para garantir a sobrevivência em um mundo competitivo, em permanente processo de transformação (VALE, 2006). Sendo assim, é necessário relatar estudos sobre redes que foram desenvolvidos em empresas de pequeno porte, visando a identificar as principais características e vantagens da formação de redes de cooperação, como será discorrido, de modo breve, na seção subsequente.

\subsubsection{Redes nas pequenas empresas: estudos empíricos}

A participação das empresas de pequeno porte e porte médio em redes de cooperação estimula o crescimento e a geração de inovações, possibilitando ganho coletivo (REBELATTO; WITTMANN, 2005; VALE, 2006). A formação de redes de cooperação e alianças estratégicas entre as organizações tem se revelado um importante estímulo para o desenvolvimento tecnológico, para a inovação e para a competitividade de pequenas empresas, produzindo efeitos positivos na sinergia de esforços conjuntos para a solução de problemas característicos de um processo de inovação, no qual o compartilhamento e a complementaridade do conhecimento possibilitam maior grau de sucesso para elas (FERREIRA; OLIVA; 2006).

Na Itália, a reconstrução e desenvolvimento do país no período pós-guerra foi conduzida com a criação de redes de pequenas e médias empresas. Naquele país, empresas com menos de 100 empregados representam 99\% do total e geram 70\% dos empregos, recebendo maior importância que grandes e médias empresas. Atualmente a Itália é considerada uma potência industrial no cenário internacional e exemplo da preponderância das redes de cooperação de empresas de pequeno porte no desenvolvimento do país (SILVA, 2005).

No Brasil, o estudo de Souza e Teixeira (2006) trouxe resultados intrigantes ao tentar investigar o papel da capacitação e da inovação na consolidação das redes de cooperação interempresariais. Suas pesquisas demonstraram que a consolidação das redes tem maior relação com a existência de inovações gerenciais, contribuindo para a evolução do modelo de gestão das empresas e a presença de práticas de aprendizagem coletiva. O nível de capacitação, tanto de empregados quanto de empresários, não pareceu estar relacionado com a consolidação das redes estudadas. O estudo foi realizado com uma amostra de oito redes de cooperação do estado do Rio Grande do Sul. Essa amostra abrangeu redes dos setores varejista, industrial e agrícola. A partir desse trabalho de campo, foi possível observar que dois aspectos foram de grande importância para a consolidação das redes de cooperação: a promoção e adoção de inovações gerenciais que contribuíram para a evolução do modelo de gestão das empresas participantes e a presença de práticas de aprendizagem coletiva dentro das redes.

Pesquisas como a de Sonaglio e Marion Filho (2006), realizada no município de Bento Gonçalves, RS, centro da aglomeração produtiva da Serra Gaúcha, apontaram que a interação entre as empresas, através de ações colaborativas a fim de minimizar a carência de competências 
e habilidades em algumas tarefas, é evidenciada pelas parcerias no desenvolvimento de inovações de processos e pela importância atribuída à troca de informações com as demais empresas do setor, como fonte de informação para a origem das inovações. Essas relações são tidas como vantajosas no sentido de minimizar custos e riscos associados à geração e incorporação de inovações.

Outro exemplo sobre a importância de redes no setor agrícola, com pequenos empreendedores, é o estudo realizado por Fort, Rasoin e Temri (2005), com sessenta empresas francesas.

A atuação dos empreendedores em redes de cooperação é uma estratégia reconhecida para a inovação em PMES, seja sensibilizando pessoas e organizações a se integrarem no processo de construção coletiva; gerando e promovendo os espaços e instâncias para a interação e contato entre diferentes atores; ajudando na definição e discussão de uma agenda comum; acompanhando, avaliando, monitorando e cobrando resultados do grupo; apoiando a estruturação e organização dos novos modelos associativos, seja assumindo o papel de gestor das novas redes (VALE, 2006; REBELATTO; WITTMANN, 2005).

Assim, ao se reunirem em rede, as empresas tornam-se mais competitivas, reduzem custos, podem compartilhar seus recursos de produção e atualizar-se mais rapidamente, conseguindo, dessa forma, concentrar seus esforços em atividades nas quais são mais eficientes (CASAROTTO FILHO; PIRES, 1999).

\section{Considerações finais}

Um dos pontos comuns mencionados pelos autores consultados é que a informação é um elemento fundamental para a criação e desenvolvimento de novas ideias. Também o conhecimento advindo dos indivíduos, bem como aquele adquirido na organização, são elementos essenciais na criação dessas ideias. Inovações podem surgir do indivíduo como também das organizações. O cenário de incertezas do ambiente no qual a organização está inserida contribui para a busca de soluções alternativas que, na maioria das vezes, tendem a serem inovadoras.

A inovação pôde ser vista aqui sob diferentes formas, como novo produto, novo serviço, novo processo, nova forma de organizar, novas formas de combinar recursos, novos mercados e, ainda, como uma melhoria contínua.

Resgatando a questão que deu origem a este ensaio, de 'como as PMES podem aumentar o nível de inovação', é possível inferir que o surgimento das novas ideias pode ser instigado pelas informações e pelos conhecimentos, fatores importantes também na interação com o ambiente externo. A criação e desenvolvimento de produtos podem dar origem a outros novos produtos, assim como também os conhecimentos novos podem ser resultados de conhecimentos já existentes e de experiências vivenciadas pelos agentes inovadores.

Transformações no contexto social e econômico servem como ativadores para a criação de processos inovadores, assim também como as inovações podem servir de desencadeador de transformações sociais e econômicas, como um processo circular e recursivo.

Empresas de pequeno porte, ainda que de uma forma tímida, também são geradoras de inovações, porém precisam ser trabalhadas de forma específica, a fim de se otimizar as condições para produção de novas ideias. O conhecimento nessas empresas é um dos fatores essenciais para o processo de inovar. 
O que pode se perceber em relação às pequenas empresas no que diz respeito à sua inter-relação com instituições de apoio, é que essas interações acontecem apenas para resolver situações de poucas empresas e sem uma troca periódica de informações e conhecimentos. Essa situação poderia ser resolvida através de uma rede, na qual a troca de informações é constante, há relacionamentos de colaboração, redução em custos de matérias-primas, entre outras vantagens, com maior probabilidade para inovar. Desse modo, as PMES também podem aumentar seu nível de inovação por meio das redes interorganizacionais.

Nas redes, os fatores que causam maior impacto são os econômicos, os de aprendizagem e os de comportamento individual e/ou organizacional. Na concepção de Rodan e Galunic (2004), estrutura de rede pode servir de procuração para informação e conhecimento heterogêneo. Informação e heterogeneidade de conhecimento possibilitam a descoberta de novas oportunidades e recursos de modo mais rápido.

É possível concluir que as ideias são instigadas por meio das relações e interação entre os indivíduos, bem como pela troca de conhecimentos, capaz de gerar novos conhecimentos e, consequentemente, transformarem-se em inovações. Atenta-se aqui para o fato de que a inovação não se constrói apenas reativamente, mas também de forma pró-ativa. A intersecção dos diversos conhecimentos resididos na pequena empresa pode proporcionar soluções para diferentes adversidades enfrentadas por ela. Inovação requer cooperação, o que pode ser construído entre organizações.

Sugerem-se, para investigações futuras, estudos empíricos, tanto quantitativos quanto qualitativos que possam corroborar empiricamente a relevância das redes e do empreendedor para a inovação nas PMEs.

\section{Referências}

BALESTRIN, A.; VARGAS, L. M. A dimensão estratégica das redes horizontais de PMEs: teorizações e evidências. RAC - Revista de Administração Contemporânea, Edição Especial, v. 8 p. 203-227, 2004.

BARBIERI, J. C. A contribuição da área produtiva no processo de inovações tecnológicas. RAE - Revista de Administração de Empresas, v. 37, n. 1, p. 66$77,1997$.

BARON, R. A.; SHANE, S. A. Empreendedorismo: uma visão do processo. São Paulo: Thomson Learning, 2007.

BAUMOL, W. The free-market innovation machine: analyzing the growth miracle of capitalism. New York: Princeton University Press, 2002.

BRUYAT, C.; JULIEN, P.-A. Defining the field of research in entrepreneurship. Journal of Business Venturing, v. 16, p. 165-180, New York: Elsevier Science Inc., 2000.

CASAROTTO FILHO, N.; PIRES, L. H. Redes de pequenas e médias empresas e desenvolvimento local: estratégias para a conquista da competitividade global com a base na experiência italiana. São Paulo: Atlas, 1999.

DACIN, M. T.; OLIVER, C.; ROY, J.-P. The legitimacy of strategic alliances: an institutional perspective. Strategic Management Journal, v. 28, n. 2, p. 169187, Fev. 2007.

DAVIDSSON, P. Researching entrepreneurship. New Jersey: Springer, 2005.

DOUGHERTY, D. Organizing for innovation. In: CLEGG, S.; HARDY, C.; NORD, W. Handbook of organization studies. London: SAGE, 1996. p. 424439.

DRUCKER, P. Innovation and entrepreneurship. New York: Harper Perennial, 1986.

Inovação e espírito empreendedor. 5. ed. São Paulo: Pioneira, 1998.

Conhecimento: sua economia e sua prosperidade. In: Sociedade pós-capitalista. São Paulo: Pioneira, 2002. p. 139-149. 
Inovação e espírito empreendedor (entrepreneurship): práticas e princípios. São Paulo: Pioneira Thomson Learning, 2005.

FERREIRA, A. A.; OLIVA, F. L. Formação de redes para o desenvolvimento tecnológico: uma experiência com empresas de base tecnológica. In: BOAVENTURA, João Maurício Gama (Org.). Rede de negócios: tópicos em estratégia. São Paulo: Saint Paul, 2006. p. 293-311.

FILION, L J. Entendendo os intraempreendedores como visionistas. Revista de Negócios, v. 9, n. 2, p. 65-79, abr./jun. 2004.

FORT, F.; RASTOIN, J-L; TEMRI, L. Les detérminants de l'innovation dans les petites et moyennes entreprises agroalimentaires. Revue internationale P.M.E., v. 18, n. 1, p. 47-72, 2005.

HOFFMANN, V E; MORALES, F. X. M. Redes de empresas aglomeradas territorialmente: os distritos industriais e seus recursos tecnológicos. In: BOAVENTURA, J. M. G. (Org.). Rede de negócios: tópicos em estratégia. São Paulo: Saint Paul, 2006. p. 279-289.

KISFALVI, V. The entrepreneur's character, life issues, and strategy making: a field study. Journal of Business Venturing, v. 17, p. 489-518, 2002.

LA ROVERE, R.L. Perspectiva das micro, pequenas e médias empresas no Brasil. Revista de Economia Contemporânea, 2001, v. 5, ed. especial. Disponível em: <http://www.ie.ufrj.br/revista/lng/pt/ artigos_publicados.php>. Acesso em: 08 jul. 2006.

LIMA, J. B. de. Novos negócios: desenvolvimento e estratégias. Lavras: UFLA/ FAEPE, 2000.

LONGENECKER, J. G. et al. Administração de pequenas empresas. São Paulo: Thomson Learning, 2007.

LUZ, G.M. S.; OLIVEIRA, S. M. M. de; ORNELAS, R.V. A. de. Informação para a competitividade e inovação tecnológica em pequenas empresas: uma análise comparativa. In: SIMPÓSIO DE GESTÃO DA INOVAÇÃO TECNOLÓGICA, 23., 2004, Curitiba. Anais... Curitiba, 2004. 1 CD ROM.

MAYO, A. Inovação e aprendizagem. In: MAYO, Andrew. O valor humano da empresa. São Paulo: Prentice Hall, 2003. p. 150-171.
MORT, G. S.; WEERAWARDENA, J; CARNEGIE, K. Social entrepreneurship: towards conceptualisation. International Journal of Nonprofit and Voluntary Sector Marketing, v. 8, n. 1, p. 76-88, 2003.

NONAKA I.; TAKEUCHI H. Criação de conhecimento na empresa: como as empresas japonesas geram a dinâmica da inovação. Rio de Janeiro: Campus, 1997.

REBELATTO, M. J.; WITTMANN, M. L. Cooperação empresarial: um estudo do cluster industrial moveleiro de Coronel Freitas - Santa Catarina. In: ENANPAD - ENCONTRO NACIONAL DOS PROGRAMAS DE PÓS-GRADUAÇÃO EM ADMINISTRAÇÃO, 29., 2005, Brasília. Anais... Brasília: Anpad, p. 1-25.

RODAN, S.; GALUNIC, C. More than network structure: how knowledge heterogeneity influences managerial performance and innovativeness. Strategic Management Journal, v. 25, n. 6, 2004.

ROSSONI, L.; TEIXEIRA, R. M. Integrando empreendedorismo, rede de relações, recursos e legitimidade: o caso da aliança empreendedora. In: ENANPAD - ENCONTRO NACIONAL DOS PROGRAMAS DE PÓS-GRADUAÇÃO EM ADMINISTRAÇÃO, 30., 2006, Salvador. Anais... ANPAD, 2006. 1 CD-ROM.

SCHUMPETER, J. Capitalism, socialism and democracy. New York: HarperPerennial, 1975.

O fenômeno fundamental do desenvolvimento econômico. In: . Teoria do desenvolvimento econômico. São Paulo: Abril, 1982.

SEBRAE. Boletim estatístico de micro e pequenas empresas. Disponível em: < http:// www.sebrae.com.br - estudos e pesquisas $>$. Acesso em: 10 jul. 2006.

SHANE, S. A general theory of entrepreneurship: the individual-opportunity nexus. North Hanpton: Edward Elgar, 2003.

SHANE, S.; VENKATARAMAN, S. The promise of entrepreneurship as a field ofresearch. Academy of Management Review, v.25, Issue 1, p.217-226, Jan. 2000. 
SILVA, C. A. V. da. Redes de cooperação no Brasil e no mundo: uma abordagem reflexiva In: EGEPE ENCONTRO DE ESTUDOS SOBRE EMPREENDEDORISMO E GESTÃO DE PEQUENAS EMPRESAS. 2005, Curitiba, Anais... Curitiba, 2005. p. 1279-1288.

SONAGLIO, C. M.; MARION FILHO, P. J. A inovação tecnológica em arranjos produtivos locais: a indústria de móveis retilíneos residenciais de Bento Gonçalves (RS). In: SIMPÓSIO DE GESTÃO DA INOVAÇÃO TECNOLÓGICA - ANPAD, 24., 2006. Gramado-RS, Anais... Gramado, 2006. p. 1-16.

SOUZA, E. C. L.de. Empreendedorismo: da gênesis à contemporaneidade In: EGEPE - ENCONTRO DE ESTUDOS SOBRE EMPREENDEDORISMO E GESTÃO DE PEQUENAS EMPRESAS. 2005, Curitiba. Anais... Curitiba, 2005. p. 134-146.

SOUZA, C. M.; TEIXEIRA, F. L. C. Papel da capacitação e da inovação na consolidação de redes de cooperação interempresariais. In: SIMPÓSIO DE GESTÃO DA INOVAÇÃO TECNOLÓGICA. ANPAD, 24., 2006, Gramado-RS. Anais... Gramado, 17-20 out. 2006. p. 1-12.

VALE, G. M. V. Empreendedores coletivos em redes organizacionais: novos agentes gerando um padrão diferenciado de competitividade. In: ENANPAD ENCONTRO NACIONAL DOS PROGRAMAS DE PÓS-GRADUAÇÃO EM ADMINISTRAÇÃO, 30., 2006, Salvador. Anais... ANPAD, 2006. 1 CD-ROM. ENANPAD, 2006.

VAN DE VEN et al. Research on the management of innovation. New York: Oxford University Press, 2000.

ZAWISLAK, Paulo Antônio. Rumo a um modelo de expectativa e potencial de inovação. In: ENANPAD - ENCONTRO NACIONAL DOS PROGRAMAS DE PÓS-GRADUAÇÃO EM ADMINISTRAÇÃO, 31., 2007, Rio de Janeiro. Anais... Rio de Janeiro: ANPAD, 2007. p 1-14. CD-ROM. 